\title{
Suprapubic Prostatectomy
}

National Cancer Institute

\section{Source}

National Cancer Institute. Suprapubic Prostatectomy. NCI Thesaurus. Code C51589.

Removal of prostate tissue following a midline abdominal incision from the umbilicus to the pubic area and a small incision of the lower anterior bladder wall. 